\title{
Measurement of the duration of high-frequency energy radiation and its application to determination of the magnitudes of large shallow earthquakes
}

\author{
Tatsuhiko Hara \\ International Institute of Seismology and Earthquake Engineering, Building Research Institute, 1 Tatehara, Tsukuba, Ibaraki 305-0802, Japan
}

(Received July 18, 2006; Revised November 9, 2006; Accepted November 28, 2006; Online published May 7, 2007)

\begin{abstract}
We have developed an algorithm to measure the duration of high-frequency energy radiation by processing the first arriving $P$-waves and then applied it to analyses of 69 large shallow earthquakes that occurred between 1995 and 2006. We compared our estimates to time differences between centroid and origin times in the Harvard CMT catalog and found that there was a good correlation between them, thereby suggesting that the measured durations are good estimates of source durations. We show that it is possible to determine magnitudes consistent with moment magnitudes in the Harvard CMT catalog using the durations of high-frequency energy radiation and maximum displacement amplitudes of the first arriving $P$-waves.
\end{abstract}

Key words: Magnitude, high-frequency energy radiation.

\section{Introduction}

It is important to rapidly determine the locations and sizes of earthquakes in order to estimate possible damage, issue tsunami early warnings, and deploy countermeasures to mitigate earthquake disasters. Although the determination of the magnitude of an earthquake is one of routine seismological data analyses, for the case of the 26 December 2004 Sumatra earthquake, it took more than $4 \mathrm{~h}$ for an estimate of $\mathrm{M}_{\mathrm{w}}=8.9$ to be issued by the Harvard University (Park et al., 2005a). This difficulty in being able to rapidly determine the magnitudes of large earthquakes has led some seismologists to propose new techniques to the rapid quantification of large earthquakes. Menke and Levin (2005) proposed determining magnitudes using relative displacements with respect to reference events. Lomax (2005) showed that it was possible to rapidly estimate rupture extent by analyzing short period $P$-wave recordings. Lomax and Michelini (2005) proposed a way to determine seismic moment using the relative rupture duration (inferred from short-period $P$-wave recordings) with respect to reference events. Park et al. (2005b) and Ni et al. (2005) both pointed out that it was possible to quantify the size of the 2004 Sumatra earthquake based on the duration of highfrequency energy radiation. Bormann and Wylegalla (2005) proposed another approach in which body wave magnitudes of subevents were summed up to calculate cumulative bodywave magnitude. Although the above-mentioned studies all showed that their techniques worked well for a number of large earthquakes including the 2004 Sumatra earthquake, the application of any one of these techniques to a data set consisting of many large earthquakes has not yet been carried out.

Copyright (c) The Society of Geomagnetism and Earth, Planetary and Space Sciences (SGEPSS); The Seismological Society of Japan; The Volcanological Society of Japan; The Geodetic Society of Japan; The Japanese Society for Planetary Sciences; TERRAPUB.
In the present study, we have developed a technique to determine the magnitudes of large earthquakes rapidly. First, we measure the duration of high-frequency energy radiation by processing of the first arriving $P$-waves; then we determine the magnitudes using measured durations and maximum displacement amplitudes.

\section{Measurement of the Duration of High- Frequency Energy Radiation}

We chose shallow ( $\leqq 50 \mathrm{~km})$ earthquakes whose moment magnitudes in the Harvard CMT catalog (http://www.seismology.harvard.edu/CMTsearch.html) were equal to or greater than 7.2 and which occurred between 1995 and 2006. The total number of earthquakes was 69. We retrieved BHZ channel waveform data of the Global Seismograph Network (GSN) stations for these earthquakes from IRIS DMC. Following Ni et al. (2005), we use data from stations in the epicentral distance range of $30-85^{\circ}$ to avoid scattering due to the upper mantle or $\mathrm{D}^{\prime \prime}$ structures (Shearer and Earle, 2004).

Following the proposal of Park et al. (2005b), Ni et al. (2005), and Lomax (2005), we measured the duration of high-frequency energy radiation through band-pass filtering of vertical component broadband seismograms. The measurement procedure consisted of the following steps:

1. Baseline correction;

2. Application of band-pass filter;

3. Square each data point;

4. Detect $P$-wave arrival;

5. Find the peak of the time series from the arrival of $P$ wave within a given time window;

6. Smooth the time series by calculating moving window average;

7. Measure the duration of high-frequency energy radiation;

8. Estimate duration of high-frequency energy radiation. 


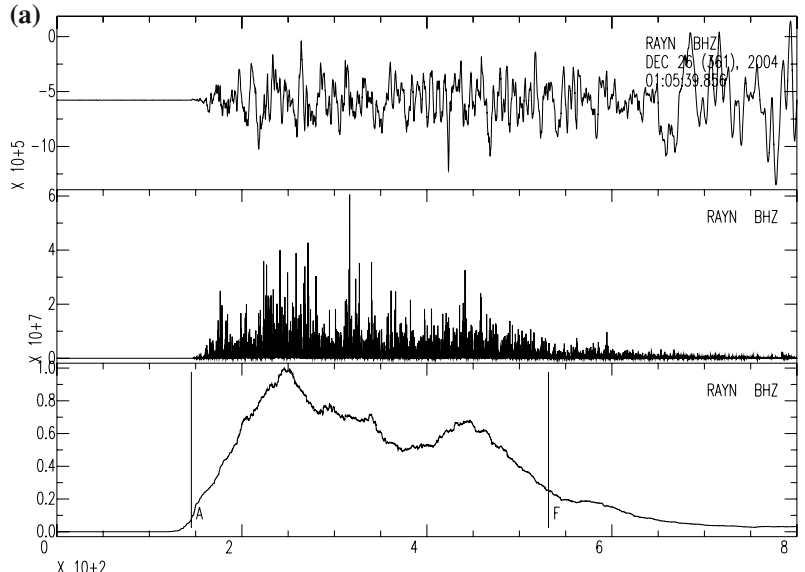

time [s]
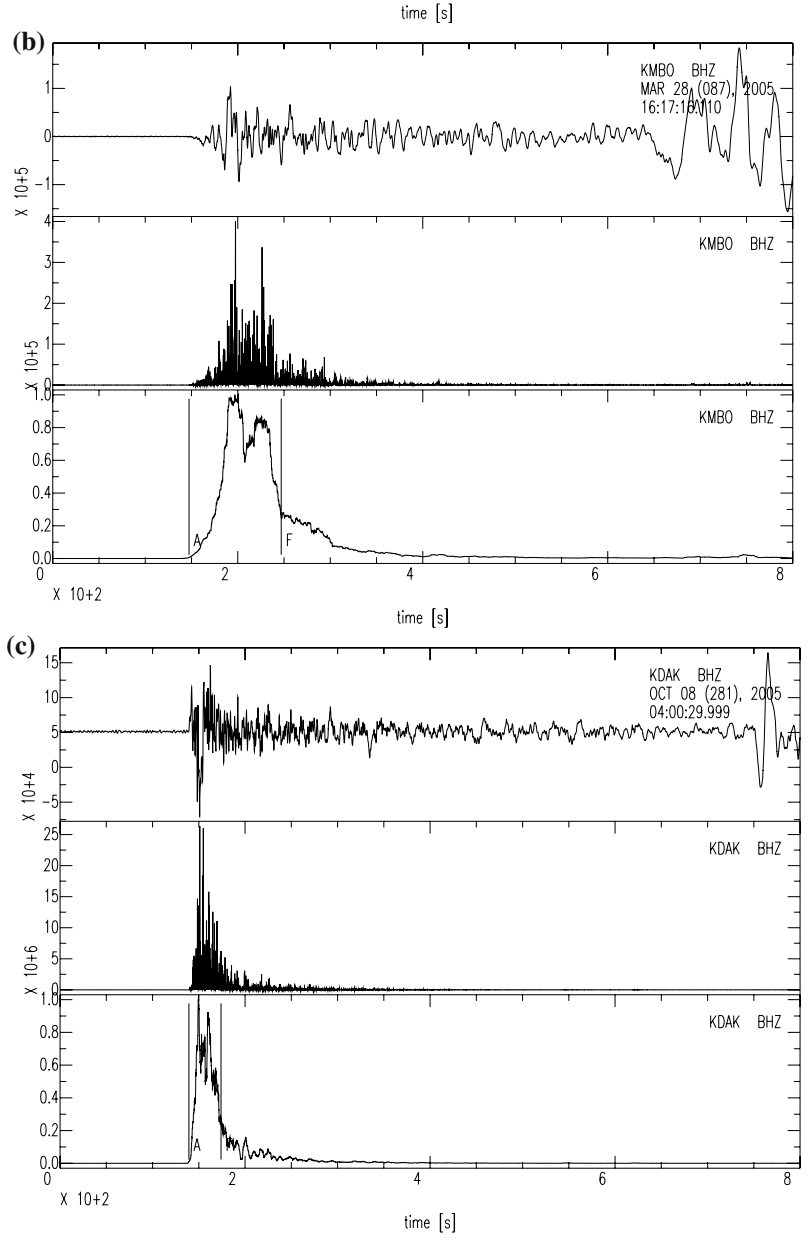

Fig. 1. Examples of measurements of high frequency energy radiation for the 26 December, 2004 Sumatra (a), the 28 March, 2005 Northern Sumatra (b), and the 8 October, 2005 Muzafarabad (c) earthquakes. The epicentral distances are 52.7, 59.9, and 80.2 degrees, respectively. The top, middle and bottom traces in (a)-(c) are an observed seismogram, a time series of squares of band-pass $(2-4 \mathrm{~Hz}$ ) filtered seismogram, and its smoothed time series (normalized by the maximum value), respectively. "A" and " $F$ " in the bottom traces denote arrivals of $P$-waves and estimated ends of high frequency energy radiation, respectively.

In the second step, we adopted the band-pass filter with corner frequencies of 2 and $4 \mathrm{~Hz}$. In the fourth step, we adopted a simple STA/LTA approach. The duration for STA was $0.2 \mathrm{~s}$, that for LTA was $10 \mathrm{~s}$, and the threshold value of the ratio STA/LTA for $P$-wave detection was 25 , respectively. After automatic pickings were carried out, we checked ob- (a)

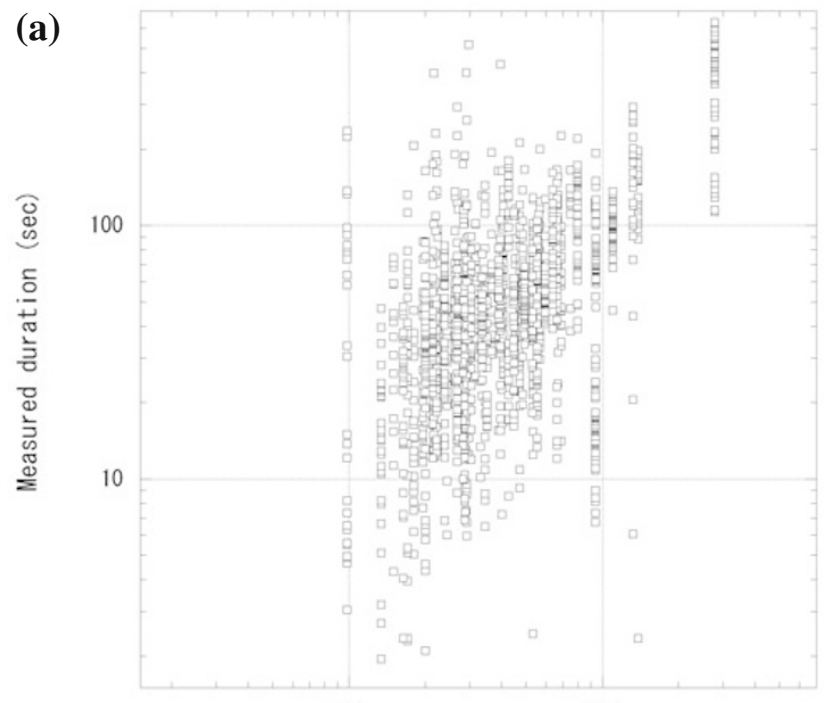

10

100

(Centroid time - origin time) x2 (sec)

(b)

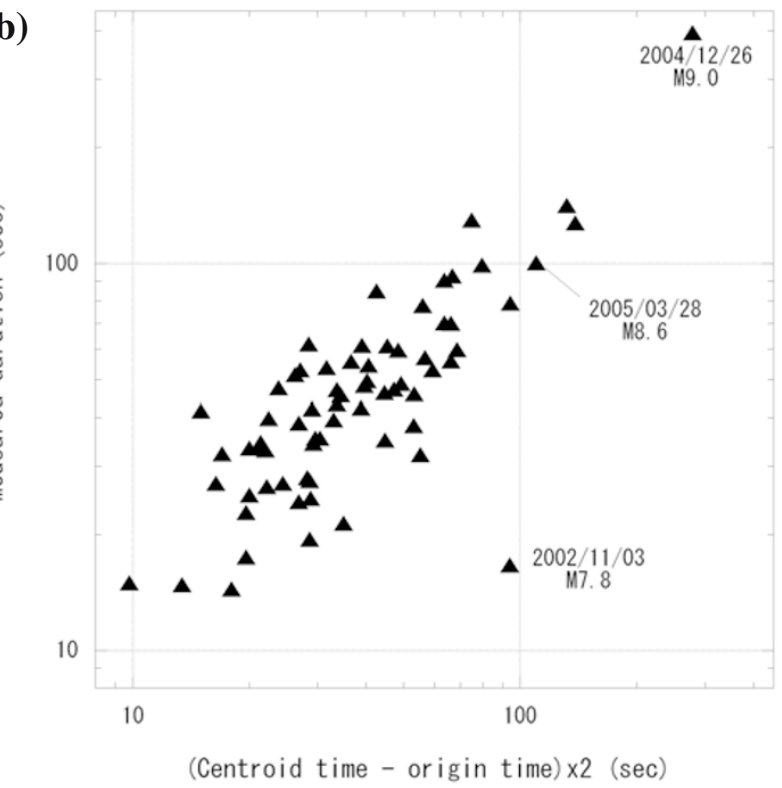

Fig. 2. Comparison of measured durations of high frequency energy radiation and differences between centroid and origin times in the Harvard CMT catalog (values of the latter are multiplied by 2): (a) all of the measurements; (b) the estimates (medians). We show dates and magnitudes for some earthquakes in (b).

served seismograms and processed time series and then corrected $P$-wave arrivals if necessary. We discarded noisy data in this step. In the fifth step, we set a time window to $400 \mathrm{~s}$.

In the sixth step, we smoothed the time series by calculating the moving window average to avoid small troughs and peaks in the measurement of the duration of high-frequency energy radiation. The time window for which the average is calculated should be varied to correspond to the source duration (i.e., a wider window is appropriate for a longer source duration, and vice versa), which is not known in this step. To obtain the order of the source duration, we used the time difference between the $P$-wave arrival time and the time when the peak is obtained in the fifth step. We set 


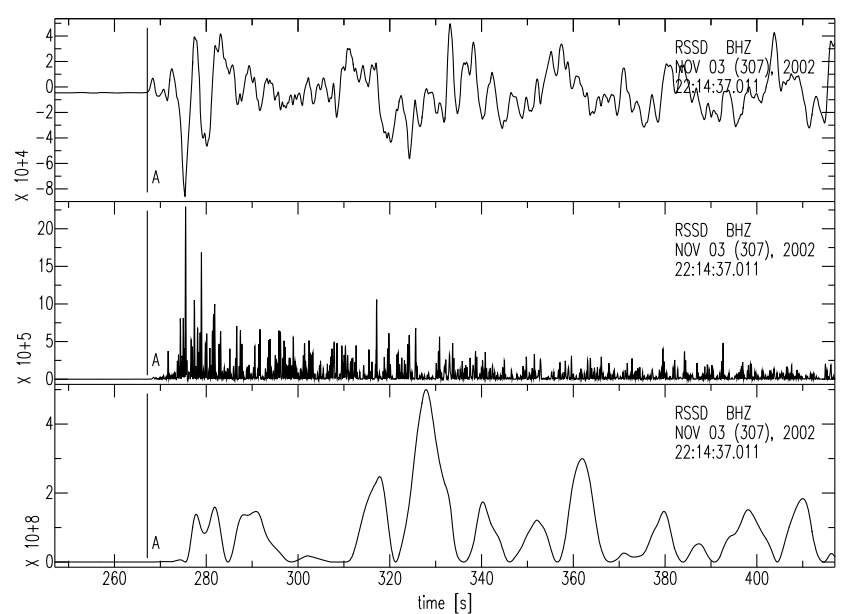

Fig. 3. The top trace is an observed seismogram (BHZ channel) recorded at the station RSSD (Black Hills, South Dakota, United States) for the November 3, 2002 Denali earthquake. The middle and bottom traces are time series of squares of the band-pass (2-4 Hz) and low-pass $(0.05$ $\mathrm{Hz}$ ) filtered seismograms, respectively.

the time window to one-sixth of this time difference.

In the seventh step, as the end time of high-frequency energy radiation, we chose the time when the amplitude of the time series calculated in the sixth step became smaller than $25 \%$ of its maximum value after the time of the peak found in the fifth step. Although the threshold value in this step is arbitrary, we show (below) that this worked well. In the eighth step, we chose the median of estimates obtained for all of the stations as an estimate for each earthquake.

Figure 1 shows examples of the data processing described above for the 26 December 2004 Sumatra $\left(M_{w}=9.0\right)$, the 28 March 2005 Northern Sumatra $\left(M_{\mathrm{w}}=8.6\right)$, and the 8 October 2005 Muzaffarabad $\left(M_{w}=7.6\right)$ earthquakes. We obtained the estimates (medians) for these earthquakes from the data shown in this figure. We did not find that the measured durations showed any significant dependence on epicentral distance. The estimates for the above three events were 396.2, 100.5 and $34.6 \mathrm{~s}$, respectively. Our estimate for the 2004 Sumatra earthquake agrees with results from previous studies (Ammon et al., 2005; Ishii et al., 2005; Krüger and Ohrnberger, 2005; Lay et al., 2005; Lomax, 2005; Ni et al., 2005; Park et al., 2005b, c), although our estimate is about $70-80 \%$ of the values reported in most of these studies. Walker et al. (2005) suggested that the source duration of the 2005 Northern Sumatra earthquake was about $120 \mathrm{~s}$, which is consistent with out estimate. Vallee (2005) suggested that the source duration of the 2005 Muzaffarabad earthquake was about $30 \mathrm{~s}$, which is also consistent with our estimate.

The difference between centroid and origin times is expected to correlate with source duration, and twice this difference is likely to be a good measure of source duration. In order to investigate whether our measurement procedure worked or not, we compared our measurements to these time differences. Although there is significant scatter in our measurement (Fig. 2(a)), the estimates (medians) correlate well with the differences between centroid and origin times (Fig. 2(b)). For the 3 November 2002 Denali earthquake,

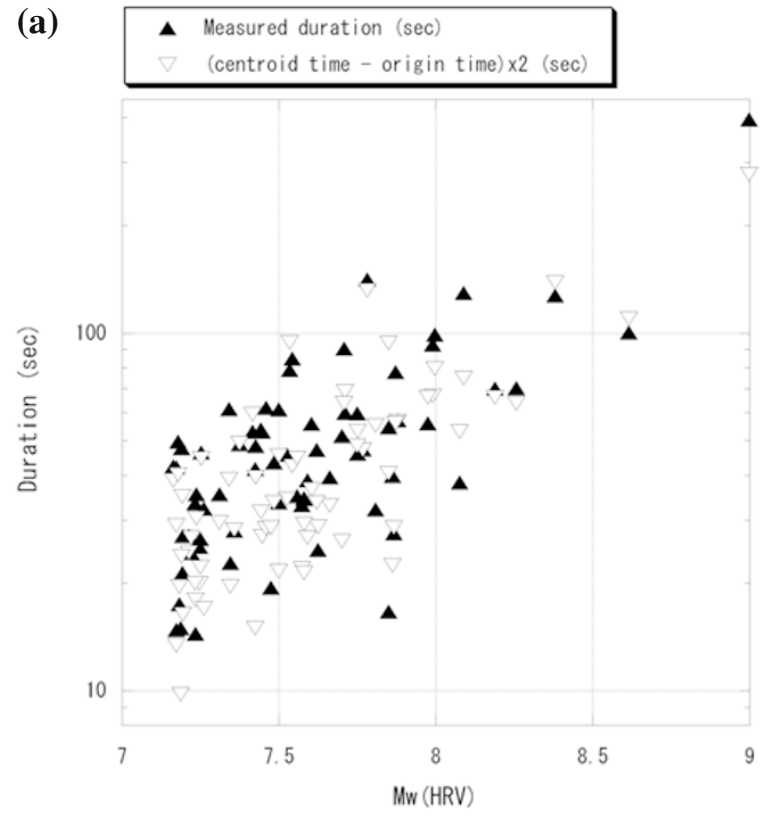

(b)

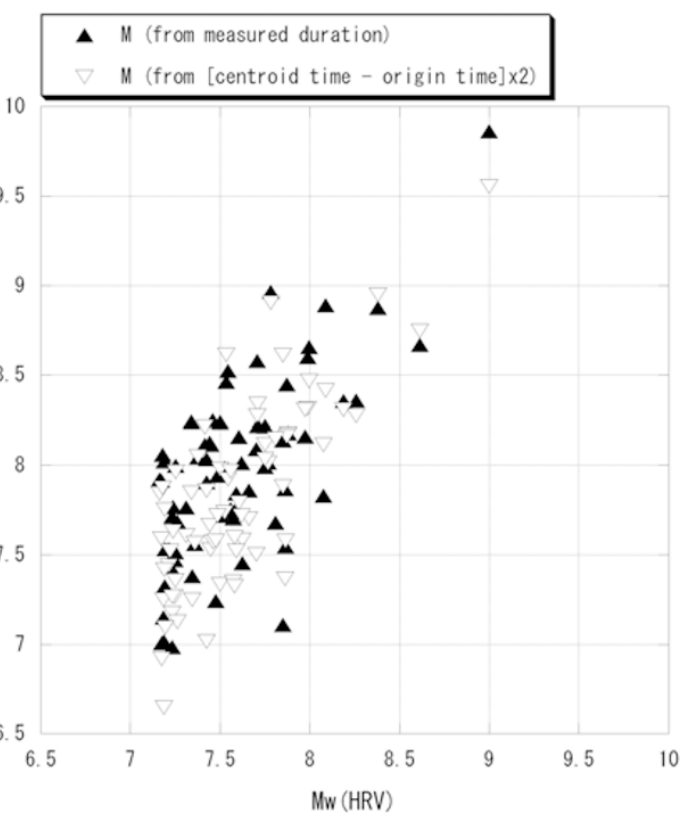

Fig. 4. (a) The measured durations of high frequency energy radiation (solid triangle) and doubled differences between centroid and origin times in the Harvard CMT catalog (open inverted triangle) are plotted as a function of moment magnitudes in the Harvard CMT catalog, respectively. (b) The magnitudes calculated using the formula by Ekström et al. (1992) for the measured durations of high frequency energy radiation (solid triangle) and doubled differences between centroid and origin times in the Harvard CMT catalog (open inverted triangle).

there is a large difference between our estimate (16.7 s) and the difference between the centroid and origin times (47.0 s; twice this value, $94.0 \mathrm{~s}$, is plotted in Fig. 2). This event consisted of the initial thrust subevent and subsequent strike slip subevents, and the moment release of the former was smaller than that of the latter (Eberhart-Phillips et al., 2003). Ozacar et al. (2003) showed that the source duration of the initial subevent was about $15 \mathrm{~s}$, that of the strike slip subevents was about $100 \mathrm{~s}$, and that the large moment release from the strike slip subevents was found at around $60 \mathrm{~s}$ after the rupture initiation. Figure 3 shows that the 


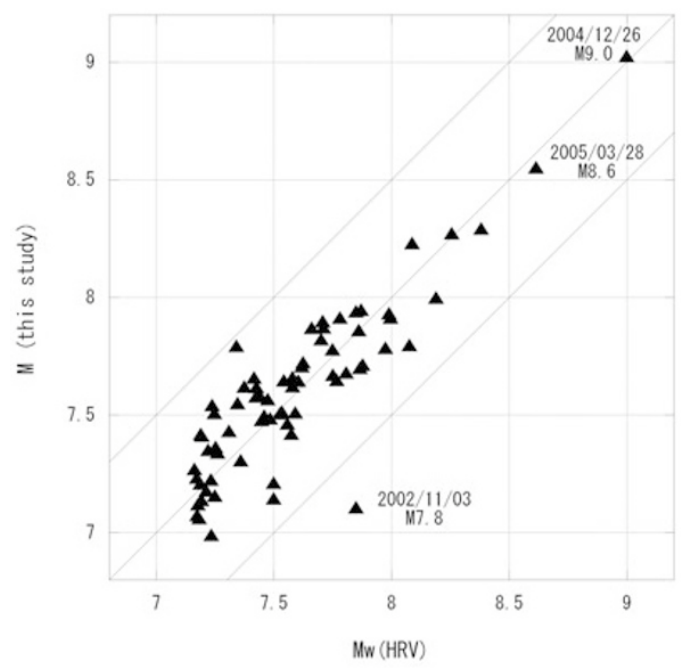

Fig. 5. Comparison of magnitudes determined in this study and moment magnitudes in the Harvard CMT catalog. We show dates and moment magnitudes for some earthquakes.

higher frequency $(2-4 \mathrm{~Hz})$ energy from the initial subevent, which appears at around $280 \mathrm{~s}$ in the middle panel, is larger than that from the strike slip subevents, which appears at around $330 \mathrm{~s}$, while the lower frequency $(<0.05 \mathrm{~Hz})$ energy from the former is smaller than that from the latter (the lower panel). This cannot be explained by the difference in the focal mechanisms and suggests that the high-frequency energy radiation from the initial subevent was more prominent than that from the strike slip subevents. Although it is possible to obtain a longer duration estimate from some stations for which the energies from the initial subevent were smaller due to the radiation pattern, such stations were few. We obtained short durations from most of the stations. This is the reason why our duration estimate is much shorter than the difference between the centroid and origin times. Our estimate is likely to correspond to the source duration of the initial thrust subevent.

\section{Determination of Magnitude}

As shown above, it is possible to obtain estimates of source durations by processing the first arriving $P$-waves. The source duration is expected to correlate with the sizes of the earthquakes. Figure 4(a) shows our estimates and the differences between the centroid and origin times in the Harvard CMT catalog as a function of $\mathrm{M}_{\mathrm{w}}$. Although a correlation is observed, the data points scatter considerably, suggesting that it will be difficult to accurately estimate the sizes of earthquakes only by the durations of highfrequency energy radiation. To obtain a better idea of this difficulty, we calculated magnitudes using our estimates and the differences between the centroid and origin times in the Harvard CMT catalog, respectively, as follows. First, in order to estimate seismic moments, we used the formula of Ekström et al. (1992):

$$
\tau=2 \times 10^{-8} \times M_{o}^{1 / 3}
$$

where $\tau$ and $M_{o}$ are the duration (in seconds) over which $95 \%$ of the seismic moment is released and seismic mo- ment (in dyne centimeters), respectively. We assigned our duration estimates or the doubled differences between the centroid and origin times in the Harvard CMT catalog to $\tau$ in this calculation. We then calculated moment magnitudes for this estimated seismic moments. Figure 4(b) shows that there is significant scatter in this magnitude estimation and that it is difficult to accurately estimate the sizes of earthquakes only by durations of high-frequency energy radiation.

We attempted to estimate the magnitudes of earthquakes using both durations of high-frequency energy radiation and maximum displacements by the following formula:

$$
M=\alpha \log A+\beta \log \Delta+\gamma \log t+\delta
$$

where $\mathrm{M}$ is an earthquake magnitude, $A$ is the maximum displacement during the estimated duration of highfrequency energy radiation from the arrival time of a $P$ wave, $\Delta$ is the epicentral distance, $t$ is the estimated duration of high-frequency energy radiation. In the case where a direct $S$-wave was expected to arrive within the estimated duration, we used a time series from the arrival time of a $P$ wave to the theoretical arrival time of an $S$-wave computed for iasp91 (Kennett and Engdahl, 1991). We performed the least square analysis to determine the coefficients $\alpha, \beta, \gamma$, and $\delta$ in the above formula. We adopted $\mathrm{M}_{\mathrm{w}}$ in the Harvard CMT catalog as values of $M$ so that magnitudes were consistent with $\mathrm{M}_{\mathrm{w}}$ in this catalog. With respect to the 26 December 2004 Sumatra earthquake $\left(M_{w}=9.0\right.$ in the Harvard CMT catalog), we set $\mathrm{M}_{\mathrm{w}}$ to 9.15 following Park et al. (2005c). We integrated the observed broadband seismograms and measured the maximum displacements (corrected by sensitivities of seismographs). We included data from stations in the epicentral distance range of less than $30^{\circ}$ to increase the number of data points. We obtained $0.79 \pm 0.03,0.83 \pm 0.05,0.69 \pm 0.03$, and $6.47 \pm 0.17$ for $\alpha, \beta, \gamma$, and $\delta$, respectively (the units of $A, \Delta$, and $t$ were meters, kilometers and seconds, respectively).

We calculated magnitudes using Eq. (1) with these parameters for all of stations and chose a median value as an estimate for each earthquake. We then compared our estimates to $\mathrm{M}_{\mathrm{w}}$ in the Harvard CMT catalog to find a good correlation between them (Fig. 5). The RMS of the differences between them is 0.18 . All of the estimates are within a range of \pm 0.5 , except for the 3 November 2002 Denali earthquake. Our estimate for this event is M 7.1, while the $\mathrm{M}_{\mathrm{w}}$ in the Harvard CMT catalog is 7.8. As mentioned above, this event consisted of an initial thrust subevent and subsequent large strike slip subevents. Since our duration estimate, $16.7 \mathrm{~s}$, corresponds to that for the initial subevent, our magnitude estimate is likely to represent the magnitude of this subevent. The magnitude estimates of the initial thrust subevent are in the range of 7.0-7.3 (EberhartPhillips et al., 2003; Ozacar et al., 2003; Dreger et al., 2004), which is consistent with our estimate.

\section{Discussion}

We have shown that it is possible to determine magnitudes consistent with $\mathrm{M}_{\mathrm{w}}$ in the Harvard CMT catalog using the durations of high-frequency energy radiation and maximum displacements with the exception of the 3 Novem- 
ber 2002 Denali earthquake. The reason for the inconsistency with this latter earthquake is that it consisted of multiple subevents and the high-frequency energy radiation from the smaller (in the sense of seismic moment release) initial thrust subevent was larger than that from the larger following subevents. This case illustrates the weakness of the procedure proposed in this study. However, it does not mean that our procedure will not work for earthquakes consisting of multiple subevents; this was the only exception among the 69 that we analyzed, and because we analyzed only large earthquakes, some or most of which are likely to consist of multiple subevents.

In the duration measurement of high-frequency energy radiation, we did not consider the effects of scattering of seismic waves. Ritter et al. (1997) studied high-frequency $P$-coda signals from teleseismic events recorded in the Massif Central, France and showed that $P$-coda signals on the vertical component records continued for around $5 \mathrm{~s}$ after the arrival of $P$-waves in the frequency band between 2$4 \mathrm{~Hz}$, while it continued for a longer time in the period band below $2 \mathrm{~Hz}$. This suggests that frequency bands higher than $2 \mathrm{~Hz}$ are relatively transparent and that effects of scattering in duration measurements are not strong. This may be one of the reasons why our estimates correlate well with the differences between centroid and origin times, although it is not sure whether this observation holds generally or only is certain cases. In order to improve the accuracy of duration measurements, it would be effective to take into account the effects of scattering using theories and techniques such as those of Korn (1997), Hock et al. (2004), Shearer and Earle (2004), and Sato (2006a, b).

In the magnitude determinations using Eq. (1), it is necessary to use maximum displacements of the first arriving $P$ waves, the duration of high-frequency energy radiation, and the epicentral distances. Since these quantities can be determined by analyzing only the first arriving $P$-waves, it is possible to quickly determine magnitudes of larger shallow earthquakes using the procedure described in the present paper.

There are some aspects to be studied in future research, such as the application of this approach to intermediatedepth and deep earthquakes as well as to tsunami earthquakes like the 1992 Nicaragua earthquake.

Acknowledgments. The author thanks Kenji Kanjo, Taro Okamoto, Shingo Watada, Robert J. Geller, Haruo Sato and Naoki Nishimura for valuable discussions on this study. The author also thanks the anonymous referees for their comments on the earlier version of this paper, which have been effective in improving the manuscript.

\section{References}

Ammon, C. J., C. Ji, H.-K. Thio, D. Robinson, S. Ni, V. Hjorleifsdottir, H. Kanamori, T. Lay, S. Das, D. Helmberger, G. Ichinose, J. Polet, and D. Wald, Rupture process of the 2004 Sumatra-Andaman earthquake, Science, 308, 1133-1139, 2005.

Bormann, P. and K. Wylegalla, Quick Estimator of the Size of Great Earthquakes, Eos Trans. AGU, 86(46), 464, 2005.

Dreger, D. S., D. D. Oglesby, R. Harris, N. Ratchkovski, and R. Hansen, Kinematic and dynamic rupture models of the November 3, 2002 $\mathrm{M}_{\mathrm{w}} 7.9$ Denali, Alaska, earthquake, Geophys. Res. Lett., 31, L04605, doi:10.1029/2003GL018333, 2004.

Ebehart-Phillips, D., P. J. Haeussler, J. T. Freymueller, A. D. Frankel, C.
M. Rubin, P. Craw, N. A. Ratchkovski, G. Anderson, G. A. Carver, A. J. Crone, T. E. Dawson, H. Fletcher, R. Hansen, E. L. Harp, R. A. Harris, D. P. Hill, S. Hreinsdóttir, R. W. Jibson, L. M. Jones, R. Kayen, D. K. Keefer, C. F. Larsen, S. C. Moran, S. F. Personlus, G. Plafker, B. Sherrod, K. Sieh, N. Sitar, and W. K. Wallace, The 2002 Denali fault earthquake, Alaska: A large magnitude, slip-partitioned event, Science, 300, 1113-1118, 2003.

Ekström, G., R. S. Stein, J. P. Eaton, and D. Eberhart-Phillips, Seismicity and Geometry of a 110-km-Long Blind Thrust Fault 1. The 1985 Kettleman Hills, California, Earthquake, J. Geophys. Res., 97, 4843-4864, 1992.

Hock, S., M. Korn, J. R. R. Ritter, and E. Rothert, Mapping random lithospheric heterogeneities in Northern and Central Europe, Geophys. J. Int., 157, 251-264, 2004.

Ishii, M., P. M. Shearer, H. Houston, and J. E. Vidale, Extent, duration and speed of the 2004 Sumatra-Andaman earthquake imaged by the Hi-Net array, Nature, 435, 933-936, 2005.

Kennett, B. L. N. and E. R. Engdahl, Traveltimes for Global Earthquake Location and Phase Identification, Geophys. J. Int., 105, 429-465, 1991.

Korn, M., Modelling the teleseismic P coda envelope: depth dependent scattering and deterministic structure, Phys. Earth Planet. Inter., 104, 23-36, 1997.

Krüger, F. and M. Ohrnberger, Tracking the rupture of the $M_{W}=9.3$ Sumatra earthquake over $1,150 \mathrm{~km}$ at teleseismic distance, Nature, 435, 937939, 2005.

Lay, T., H. Kanamori, C. J. Ammon, M. Nettles, S. N. Ward, R. C. Aster, S. L. Beck, S. L. Bilek, M. R. Brudzinski, R. Butler, H. R. DeShon, G. Ekström, K. Satake, and S. Sipkin, The great Sumatra-Andaman earthquake of 26 December 2004, Science, 308, 1127-1133, 2005.

Lomax, A., Rapid estimation of rupture extent for large earthquakes: Application to the 2004, M9 Sumatra-Andaman mega-thrust, Geophys. Res. Lett., 32, L10314, doi:10.1029/2005GL022437, 2005.

Lomax, A. and A. Michelini, Rapid determination of earthquake size for hazard warning, EOS Trans. AGU, 86(21), 202, 2005.

Menke, W. and V. Levin, A strategy to rapidly determine the magnitude of great earthquakes, Eos Trans. AGU, 86(19), 185, 2005.

$\mathrm{Ni}, \mathrm{S}$., H. Kanamori, and D. Helmberger, Energy radiation from the Sumatra earthquake, Nature, 434, 582, 2005.

Ozacar, A. A., S. L. Beck, and D. H. Christensen, Source process of the 3 November 2002 Denali fault earthquake (central Alaska) from teleseismic observations, Geophys. Res. Lett., 30(12), 1638, doi:10.1029/ 2003GL017272, 2003.

Park, J., R. Butler, K. Anderson, J. Berger, H. Benz, P. Davis, C. R. Hutt, C. S. McCreery, T. Ahern, G. Ekström, and R. Aster, Performance review of the global seismographic network for the Sumatra-Andaman megathrust earthquake, Seismol. Res. Lett., 76, 331-343, 2005 a.

Park, J., K. Anderson, R. Aster, R. Butler, T. Lay, and D. Simpson, Global seismographic network records the great Sumatra-Andaman earthquake, EOS Trans. AGU, 86(6), 57, 2005b.

Park, J., T.-R. A. Song, J. Tromp, E. Okal, S. Stein, G. Roult, E. Clévédé, G. Laske, H. Kanamori, P. Davis, J. Berger, C. Braitenberg, M. V. Camp, X. Lei, H. Sun, H. Xu, and S. Rosat, Earth's free oscillations excited by the 26 December 2004 Sumatra-Andaman earthquake, Science, 308, $1139-1144,2005 \mathrm{c}$.

Ritter, J. R. R., P. M. Mai, G. Stoll, and K. Fuchs, Scattering of teleseismic waves in the lower crust Observations in the Massif Central, France, Phys. Earth Planet. Inter., 104, 127-146, 1997.

Sato, H., Synthesis of vector-wave envelopes in 3-D random elastic media characterized by a Gaussian autocorrelation function based on the Markov approximation: Spherical wave case, J. Geophys. Res., 2006a (in press).

Sato, H., Synthesis of vector wave envelopes in three-dimensional random elastic media characterized by a Gaussian autocorrelation function based on the Markov approximation: Plane wave case, J. Geophys. Res., 111, B06306, doi:10.1029/2005JB004036, 2006 b.

Shearer, P. M. and P. S. Earle, The global short-period wavefield modelled with a Monte Carlo seismic phonon method, Geophys. J. Int., 158, 1103-1117, 2004.

Vallée, M., $\mathrm{M}_{\mathrm{w}}=7.7$ 05/10/08 Pakistan earthquake, http://www-geoazur. unice.fr/SEISME/PAKISTAN081005/note1.html, 2005.

Walker, K. T., M. Ishii, and P. M. Shearer, Rupture details of the 28 March 2005 Sumatra $M_{w} 8.6$ earthquake imaged with teleseismic P waves, Geophys. Res. Lett., 32, L24303, doi:10.1029/2005GL024395, 2005.

T. Hara (e-mail: thara@kenken.go.jp) 